\section{Georgiana M. Bonser}

Dr Georgina M. Bonser (née Duthie), MD (Manchester), FRCP (London), a leading woman doctor engaged in cancer research in England, died on 9 June 1979 at the age of 81 .

She was born on 5 May 1898 and studied medicine in Manchester University and at King's College Hospital, London, qualifying in 1920. By 1923, she had been awarded her MD with distinction and won a travelling fellowship which enabled her to spend a year at the Institut Pasteur in Paris. While there, she met her future husband, Kenneth Bonser, an architect. In 1927 she began her long association with Leeds University and its hospitals. Fortuitously, her interests were channelled into cancer research by her chief, Professor Matthew Stewart. She was a woman with a strong sense of purpose who saw two challenges in her life, the problems of cancer and the need for women in the medical profession to establish their rightful place in an essentially male preserve. Dr Bonser's efforts were eventually to be recognised by her election to the chairmanship of the Leeds branch of the British Medical Association, in 1953, and presidency of the Medical Women's Federation in 1959, which speak for her tenacity and political acumen.

But to appreciate her real achievement, it must be recalled that cancer research, when she began, paid the handsome salary of $£ 200$ a year and it was necessary for her to take a part-time job in pathology in order to have enough money to live on. She held several posts in the Leeds hospitals and university until she finally became reader in experimental pathology and cancer research and a consultant pathologist at St. James's Hospital and lived to see this hospital translated from a poor law institution to a modern teaching hospital.

Dr Bonser's contribution to knowledge has been in the studies of chemically induced carcinogenesis of the bladder. Although the association of bladder cancer and the dyeing industry had been established in the late nineteenth century, all efforts to induce bladder tumours with the products from the dyeworks or urine of workers affected with bladder cancer were a failure. Dr Bonser, in 1937, reviewed these disappointing results which were somewhat reminiscent of the research for some of the more elusive infective agents some 50 years previously. Hueper's report that the feeding of large doses of B-naphthylamine to dogs produced bladder cancer was the turning point. By 1943, Dr Bonser reported that the following feeding purified ß-naphthylamine to dogs for 5 years, bladder cancer could be induced. This helped to remove suspicion from $\alpha$-naphthylamine and identify one hazard in the dyeing industry.
She soon realised that the dog was too cumbersome and expensive an animal for research and concentrated on developing models in small animals. From this time, progress was much more rapid as the waiting time to see the result of an experiment was then a matter of one to two years. Dr Bonser's team confirmed that 2-acetylaminofluorene when fed to mice was a bladder carcinogen; this was the first in a long series of experiments that resulted in her being an expert on the interpretation of the pathology of the bladder in laboratory animals.

It became clear to Dr Bonser that she needed specialist help; in part it came from Professor L.N. Pyrah, a urological surgeon who helped with surgical techniques in the animals but the whole programme really became most effective when she recruited D.B. Clayson, a young chemist and J.W. Jull, a biologist to help her. There then followed a long haul in which the metabolism of several potential bladder carcinogens was studied and the carcinogenic properties of their various derivatives tested in her systems. An important part of the techniques developed by Dr Bonser's team was the direct implantation of carcinogens in a variety of different vehicles into the bladders of rats and mice. The net result of their efforts over the next 15 years was to put one part of the bladder carcinogenesis story on to a sound scientific basis. Its eventual impact reached far beyond the dyeworks to embrace the workers in rubber and cable making industries who came into contact with B-naphthylamine. Dr Bonser's strength lay in a sense of purpose, her strong discipline and sound knowledge of general pathology as well as her natural clinical practice; in 1961 she was co-author of a book on the pathology of breast cancer.

In the University her research was solidly based on her nose for a good experiment and skill at being able to interprete the results. Many others who have delved in this field had been hopelessly wrong as they could not tell the difference between hyperplasia of the bladder mucosa from that of early carcinoma. One of her last tasks after her retirement was the writing with one of her former pupils, of a chapter on the pathology of the bladder in experimental animals in the handbook produced by the International Agency for Cancer Research.

Today, with the flood gates open to pour money into testing for carcinogens, it is salutary to reflect that in the smoke and grime of pre-war Leeds, this small, determined and formidable woman was quietly laying the corner stones of the work. The combination of her keen mind and dogged persistence was rewarded by achieving a few lasting goals, but what is most important, she was one of those pioneering women scientists ahead of her time. Georgiana Bonser had been a great credit to her University and dealt a nasty jolt to male chauvinism in medicine, both of which must have given her the satisfaction of a life well spent.

Edward H. Cooper

\section{Sir Peter Venables}

Sir Peter Venables died at his home in Birmingham on Sunday 17 June 1979 . He was 74. His passing leaves a gap in the world of education in Britain that cannot easily be filled.

Peter Venables started his career as a chemist; to use his own words as "a mere chemist." $\mathrm{He}$ emerged from Liverpool University in 1925 with a first-class honours degree in chemistry. It was typical of the man, and of his later career, that, despite the quality of his first degree, he should, before embarking on study for a $\mathrm{PhD}$, have spent a year acquiring an Education Diploma. He then spent four years in research, obtaining a $\mathrm{PhD}$ in 1928 followed by 2 years of postdoctoral work.

For the next 11 years his career followed the standard pattern of a teacher in higher education. First as a Lecturer and later as a Senior Lecturer in the Leicester College of Technology (now the Leicester Polytechnic) and then as Head of the Science Department at the South-East Essex Technical College he continued to teach and to carry out research in chemistry. But while at Leicester his lifelong interest in the visual arts was stimulated by the close contacts he made with the staff of the College of Art.

But it was in 1941, at the age of 37 , that he took the critical step that was to determine the path of his future career. He accepted the post of Principal of the Municipal College at Southend-on-Sea. This was a move into academic administration. From now on Peter Venables was not "a mere chemist"; he had entered the curious world where education and administration are blended. Academic excellence is a necessary passport to enter this world but in it academic work must take second place (and often third or fourth place), yielding to the need to provide leadership to a company of men and women characterised by independence of mind and often of equal independence of action. He had the qualities required for success, an absolute integrity of purpose which he would pursue, as the occasion required, with consummate patience, with a formidable show of strength or even, where necessary, with guile. He had a mischievous wit and could school his countenance to betray no expression whatsoever as he uttered his most outrageous quips. All in all he inspired in his friends and colleagues both an absolute trust and a deep affection, a combination that inevitably makes a leader of men, and a leader he was to be for the rest of his career. 